\title{
Theorizing E-Commerce Business Models: On the Impact of Partially and Fully Supported Transaction Phases on Customer Satisfaction and Loyalty
}

\author{
Maria Madlberger \\ Webster Vienna Private University \\ Austria \\ maria.madlberger@webster.ac.at
}

\author{
Sabine Matook \\ University of Queensland
}

\begin{abstract}
Although considerable research has been conducted on the definition and classification of ecommerce business models, little research has integrated the support and impact of distinct transaction phases within e-commerce business models. Indeed, any channel design decisions depend on the arrangement of the three transaction phases, viz. information phase, agreement phase and fulfilment phase. Whereas in literature, a complete support of transaction phases is implicitly assumed, in practice, e-commerce firms exist that consciously do not support all three transaction phases through the online channel. In cases for which only certain phases are supported in one channel, the customer is required to switch to another channel to complete the transaction. To gain an initial understanding of the relevance of transaction phases, we examine the influence of transaction phase support in one channel on satisfaction and reuse intention of an e-commerce website under consideration of users' prior experiences. We conduct a laboratory experiment involving two e-commerce business models that differ only in the number of supported transaction phases via the online channel. Empirical data was analysed using a Bayesian network approach. Our analysis indicates the types of users who value partial support compared to those users who prefer full support of transaction phases. The results will assist firms in meeting future challenges regarding user engagement and attraction to their online stores.
\end{abstract}

Keywords: Electronic commerce business model; transaction phases; channel design; channel switching; customer satisfaction; reuse intention; tourism industry; Bayesian network

\section{Introduction}

After years of constant growth, mobile and electronic commerce (e-commerce) have reached a significant level and account for a substantial share of overall retail sales (eMarketer 2015). Firms of all sizes use Internet technologies for conducting their business transactions and customer interactions online (Slade \& Van Akkeren 2002). Recent figures make this development evident: as of 2015, e-commerce sales worldwide amounted to 1.67 trillion US\$ and sales are predicted to grow to 3.58 trillion US $\$$ by 2019 (Statista 2016). Indeed, projected annual e-commerce sales are expected to reach growth rates of between $18.7 \%$ and $22.7 \%$ each year and the worldwide online purchase penetration - that is, the percentage of online buyers among Internet users - is now 51.5\% (eMarketer 2015). Mobile commerce via locationindependent devices is also growing, especially among younger demographics whereby, in the 18-24 age group, $65 \%$ of survey respondents said they use their smartphones for conducting purchasing transactions (Lindner 2016). These figures illustrate the advancement of mobile and e-commerce, which has been recently enhanced through multi-channel customer engagement (Piotrowicz \& Cuthbertson 2014). Providing multiple channels offers customers various access points and interaction opportunities that can ultimately increase customer satisfaction and loyalty (Wallace et al. 2004). Companies enjoy a number of benefits through a multi-channel design that are not present in a single channel design, such as closer customer relationships, more tailored products, better service offerings and potentially more sales 
(Steinfield et al. 2002). Decisions about how to engage with customers have become even more important for companies given the advent of social media as an additional channel (Dalla Pozza 2014; Piotrowicz \& Cuthbertson 2014; Verhoef et al. 2015) and the increased functionalities of mobile devices (Bang et al. 2013; Huang et al. 2016).

Channel design is a core element of a company's e-commerce business model whereby the focus is on the purchasing transaction. An e-commerce business model reflects the business logic of a company (Daidj 2015; Morris et al. 2005) and explains how e-commerce is integrated into the company's wider business strategy (Teece 2010). Chesbrough \& Rosenbloom (2002) note that a simplified view of a business model is that it represents the company's business activities "by which a company can sustain itself, that is, generate revenue" (p. 529). Hence, a business model describes "the content, structure and governance of transactions designed so as to create value" (Amit \& Zott 2001, p. 511). Business models that consider a multichannel strategy implicitly utilize the concept of segmenting the customer transaction into a number of individual phases. Existing research has identified different transaction phases, viz. the information, agreement and fulfilment phases (Choudhury \& Karahanna 2008; Shankar et al. 2003; Wiesel et al. 2011). Once a transaction phase has been completed, customers are free to switch to another channel to continue the transaction (Pookulangara et al. 2011). For example, customers can initiate a purchasing transaction on a smartphone but may choose, due to limitations of the mobile channel (e.g., screen or image size), to switch to a desktop computer to finalize the transaction. Similarly, customers may be invited to search for and select a product on a company's website but, in order to complete the transaction, are forced to switch the channel and establish a direct communication channel with the company.

Despite a large body of research on e-commerce business models on the one hand and transaction phases in e-commerce on the other hand, both research areas have been studied by the literature isolated from each other. In fact, research on e-commerce business models has so far paid little attention to the concept of distinct transaction phases. More specifically, many studies on e-commerce business models do not differentiate between separate transaction phases and instead understand the purchasing transaction as a monolithic, indispensable component (e.g., Osterwalder et al. 2005; Zott et al. 2011). How companies might offer customers different channels and allow for channel switching is not detailed in ecommerce business model descriptions. In fact, existing research on the topic implicitly suggests that one channel supports all transaction phases, while empirical research shows that most channel design solutions offer multiple channels through which customers can complete their transactions (Zott \& Amit 2007; Zott \& Amit 2010).

In contrast to the academic debate, some e-commerce firms strategically position their business models to focus on increasing user engagement (Attfield et al. 2011). To achieve this objective, they implement forced channel switching by only supporting parts of a transaction in one channel (e.g., mobile or online) and allowing customers to complete a transaction only after switching to a direct customer-company communication channel. This channel switching is implemented despite the technical abilities of the website operators to support a full transaction phase approach on their websites. Examples in practice of such business models that include such forced channel switching can be found in the tourism industry, whereby the booking of a flight or hotel package is only possible through direct interaction with a company service operator. In such cases, the forced switching is from the online or mobile channel to the direct customer-company communication channel via email.

A specific example of a business model that offers only partial transaction support with forced channel switching is Flightfox (flightfox.com). Flightfox.com wishes its customers to complete the transaction with its personal selling channel. Therefore, customers first submit their planned itinerary on the website and, subsequently, an operator is assigned who contacts each customer to search for flights and carry out the booking once the cheapest flight offer has been found. Another example for a partial transaction support is the Australian travel agency Flight Centre that processes holiday packages only through direct customer-company communication, despite customers' ability to search through available deals and request quotes on the company's website (flightcentre.com.au/holidays). Further examples of forced 
channel switching include special conditions that make the switch necessary, such as customers' payment options (e.g., a Hawaiian airline requires customers to book an interisland flight via their call centre if they do not have a US credit card), time constraints (e.g., allowing the purchase of tickets for an event by phone only if the event date is in the near future) or availability constraints (e.g., despite availability, vacation packages may no longer be bookable through the online channel closer to the travel date, necessitating customers' direct contact with the travel agent).

The forced channel switching represents an e-commerce business model by which the company seeks to maximize customer service and user engagement through personal interactions with customers (Lehmann et al. 2012; van Doorn et al. 2010). This strategic decision is made consciously and does not take full use of technological opportunities to provide full support via multiple channels for customers. The enhanced interaction intensity that results from the forced channel switching allows for the offering of additional services to customers and provides opportunities for extra value creation. However, e-commerce business models that employ such forced channel switching have not yet been discussed in the literature. Hence, the question remains as to how customers perceive the partial support of a transaction in one channel and the subsequent forced channel switching. In particular more clarification is needed whether an increased service level through personal interaction can offset the inherent delay of completing the transaction which can be perceived as a flaw by customers (Everard \& McCoy 2010). Furthermore, the literature is silent as to which types of customers prefer an e-commerce business model by which one transaction can be completed in one channel (full transaction support) compared to switching the channel after the first or second phase (partial transaction support). On the one hand, customers may appreciate the extra service offerings and closer attachment to the company provided by partial transaction support. On the other hand, customers may prefer to complete a transaction swiftly in one channel, especially the online and mobile channels. Consequently, this study seeks to fill the gaps in the literature by examining how e-commerce business models, which support transaction phases via the online channel, influence to different extents customer satisfaction and reuse intention in light of user experience considerations.

The limited body of literature on transaction phase considerations in e-commerce business models and the research gap on e-commerce business models that incorporate forced channel switching as a means of enhancing customer engagement motivated our research. Consequently, we examine extant research on e-commerce business models and transaction phases in e-commerce. We draw on theoretical work regarding transaction phases in ecommerce settings (Choudhury \& Karahanna 2008; Veit et al. 2014; Wiesel et al. 2011) and channel expansion theory (Carlson \& Zmud 1999). Subsequently we empirically test the research model with an experimental research design in the domain of online travel websites. Motivated to focus on causality (Lauría \& Duchessi 2007; Zheng \& Pavlou 2010), the data are analysed using a Bayesian network approach. Our findings contribute to the information systems (IS) and marketing literature by providing an improved understanding of user satisfaction and the reuse intention of an online store's customers, considering varying degrees of transaction phase support. The practical implications of this research are relevant for ecommerce companies and customers alike, as they facilitate improving firms' e-commerce presence so as to achieve higher levels of customer satisfaction.

\section{Background}

\subsection{The Concept of Transaction Phases}

Transactions aim to initiate, arrange and complete contractual agreements between trading partners (Schmid \& Lindemann 1998). A transaction can be split into a number of transaction phases. Indeed, when analysing purchasing processes, neither the marketing literature (Bunn 1993; Kotler \& Keller 2015) nor the IS literature (Choudhury \& Karahanna 2008; Pavlou \& Fygenson 2006) considers a transaction to be a monolithic block, but rather a series of transaction phases. This "purchase funnel" captures the customer's decision-making process 
towards the purchasing act, whereby the number of phases depends on the level of granularity (Wiesel et al. 2011).

Conceptually, a transaction is composed of three stages, viz. the pre-purchase, purchase and post-purchase phases (Wiesel et al. 2011). These stages have been captured in the literature as (1) information phase, (2) agreement phase and (3) fulfilment phase (Bauer et al. 2006; Chen \& Chang 2002; Holzmüller \& Schlüchter 2002; Kalakota \& Whinston 1997; Yu et al. 2002). It should be noted that, in the literature, multiple variations to this three-phase model exist, for example by adding a fourth, after-sales phase (Bauer et al. 2006; Di Noia et al. 2004; Schubert 2002) or by splitting the agreement phase into two phases: the intention and contract phases (Anagnostopoulos et al. 2004). Nevertheless, in this research we focus on the three-phase model because it is the most generic and independent of particular industries or supply chain members.

In the information phase, where all pre-purchase activities take place, information acquisition is central to aiding in the customer's decision-making and preparation of the purchasing act (Choudhury \& Karahanna 2008; Pavlou \& Fygenson 2006). This initial stage is largely cognitive and represents the mental processes of forming an intention to purchase a product based on the gathered information (Wiesel et al. 2011). In the agreement phase, the actual purchase is made (Pavlou \& Chai 2002; Steinfield et al. 2002) and, thus, this phase is a conative activity (Wiesel et al. 2011). The fulfilment phase includes the post-purchase activities and covers after-sales services (Di Noia et al. 2004; Schubert 2002; Steinfield et al. 2002) and after-purchase evaluations (Choudhury \& Karahanna 2008). The three transaction phases are presented in detail as follows and summarized in Figure 1 (Choudhury \& Karahanna 2008; Kim \& Lee 2002; Veit et al. 2014; Wiesel et al. 2011; Zumpe \& Madlberger 2007b):

1) In the information phase, also referred to as information search, customers look for information about offered products and services, as well as companies that offer them. In e-commerce, this phase begins when prospective customers enter a mobile or ecommerce system (Kim \& Lee 2002). Information search includes product and price comparisons as well as checking the availability of products or services. Once an offer is submitted the information phase is concluded and the transaction proceeds to the next phase.

2) In the agreement phase, the customer interacts with the seller by agreeing upon purchasing conditions. Key parameters are product prices, product characteristics, terms of delivery and terms of payment. Once both the customer and the seller accept the agreed upon conditions, a legally binding contract is established. This activity constitutes the end of the agreement phase, requiring both parties to fulfil the conditions of the contract (delivery and payment, respectively). This phase is carried out entirely by means of electronic communication.

3) The fulfilment phase comprises the fulfilment of the contractual obligations set up in the preceding agreement phase. It consists of activities such as transportation of goods or download enablement, storage, packaging and payment. In cases involving services, fulfilment includes reservations and booking, or the provision of a ticket that acts as a document entitling the customer to consume the service. The purchasing transaction is completed once the fulfilment phase is finished, although after-purchase phases are still possible (e.g., after-sales service). 


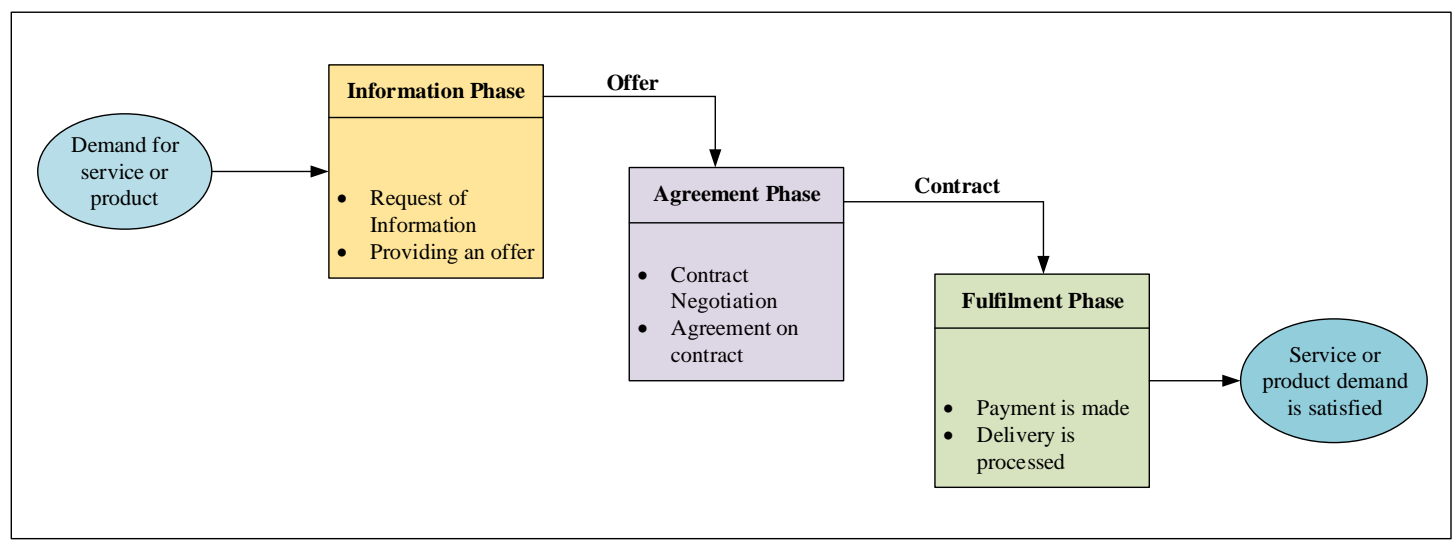

Figure 1. The e-commerce transaction phases model (Zumpe \& Madlberger 2007b; Zumpe \& Madlberger 2007a)

\subsection{E-Commerce Business Models}

Comprehensive research has been conducted on the structure, functioning and impacts of ecommerce business models over the past decade (Choudhury \& Karahanna 2008; Hedman \& Kalling 2003; Veit et al. 2014). The findings are characterized by a variety of methods, classifications, frameworks and components. For example, Wang et al. (2016) provide an empirical analysis of success factors of group-buying websites to illustrate a business model that differs from conventional business-to-consumer online stores. Indeed, e-commerce business models can differ substantially in their effect on sales generation because important factors such as price reductions or dynamics in sales processes can look very differently (Wang et al. 2016). Considering this rich body of work, it comes as a surprise that e-commerce business models are described as the most discussed yet least understood concepts in the ecommerce field (Veit et al. 2014). Consequently, we see a need to provide a detailed and comprehensive definition of e-commerce business models as we understand them in this research. Following Osterwalder et al. (2005), we define an e-commerce business model as " $a$ conceptual tool that contains a set of elements and their relationships and allows expressing the business logic of a specific firm [...] being a description of the value a company offers to one or several segments of customers and of the architecture of the firm and its network of partners for creating, marketing, and delivering this value and relationship capital, to generate profitable and sustainable revenue streams" (p. 3).

The value provided by an e-commerce business model is decisive for customers' choice of the e-commerce channel (Lim 2014) and, as a further consequence, also for the reuse intention (Adapa \& Cooksey 2013; Wang et al. 2016). Nowadays e-commerce business models are often based on multiple channels, also referred to as bricks and clicks business models (Herhausen et al. 2015). Several studies consider channels a part of a business model's value network that describes how companies conduct transactions through coordination and collaboration with other parties (Al-Debei \& Avison 2010). The design of a company's distribution channels is a strategic company decision because it impacts on the organization's business model and any changes to the channel design alter customer target groups and propositions of shopping value, entailing a redesign of the value chain. As framing theory suggests, location and presentation of content can determine the specific focus of a website (Parker et al. 2014), hence particular features of e-commerce business models can be emphasised this way. E-commerce business models are, however, influenced by decisions not only regarding the provision of different channels but also regarding whether they are run separately or are integrated (Cao 2014). Integrated channels allow customers to switch between them, whereas separate channels do not provide this functionality.

A highly relevant phenomenon in multi-channel business models is customers' channel switching behaviour (Forman et al. 2009; Gupta et al. 2004; Pookulangara et al. 2011; Viswanathan 2005). Each channel has its respective advantages that potentially drive 
customers to terminate a purchasing process in one channel only to continue it in another (Gupta et al. 2004; Kollmann et al. 2012). Particular advantages of online over offline channels include saving time and effort, as well as search facilitation and comparison of products (Rohm \& Swaminathan 2004), more comprehensive product information and a larger product assortment (Alba et al. 1997). Customers can enjoy additional benefits of the mobile channel that go beyond those benefits of the online channel. For example, transactions via the mobile channel benefit from the ubiquity of mobile devices, which increases customers' opportunities to shop independently of their location. Yet limitations in the size of mobile devices, together with potentially limiting situational factors (e.g., time pressure, lack of concentration), can drive customers back to the online channel (Bang et al. 2013). Another new channel for the acquisition of products and services involves Web 2.0 social media technologies (Liang \& Turban 2011). Social media applications, such as LinkedIn, Facebook and Twitter, provide features for users to initiate and complete transactions. A strength of social media-enabled commerce (i.e., social commerce) is the availability of the known crowd of close others in the form of friends, contacts or followers. These people are often powerful advisers for a consumer's purchasing decision, as research on word of mouth has shown (Amblee \& Bui 2011; Matook et al. 2015). In contrast, offline channels demonstrate the strengths of human interaction and in-store experience, providing product feeling, touching and testing possibilities prior to purchase, the satisfaction of immediate needs and an established infrastructure (Prasarnphanich \& Gillenson 2003).

The increased number of available channels and the channel switching phenomenon draw attention to the issue of transaction phase support. A number of studies examined the components of different e-commerce business models and studied their use, effectiveness and attractiveness for customers (for a detailed discussion of these prior research studies see Zumpe \& Madlberger 2007a). Most of these studies conclude that a lack of transaction focus in e-commerce business models exists and highlight the need for more research on the impact of transaction phases on the purchasing process. For example, Pateli \& Giaglis (2004) define a research agenda on e-commerce business models and request clarification of the relationship between e-commerce and the related business transactions. In their understanding, if a business model does not encompass the concept of transactions and how different phases are to be supported, the business logic of the company is imperfect (Hammer \& Champy 2003). Similarly, in a recent publication, Veit et al. (2014) theorize about the role of technology in linking business partners and customers via distinct channels to ensure value creation through these models. The authors again call for future research to foster a better understanding of channel composition and transaction support. In doing so, they highlight the persistent lack of theoretical and empirical studies in the literature about transaction phases in e-commerce business models. Consequently, we concur that an e-commerce business model that lacks discussion of transactions, especially regarding transaction phases and how they are supported in different channels, is incomplete from a theoretical perspective.

\section{Hypotheses Development}

\subsection{Impact of Transaction Phase Support on Customer Satisfaction and Usage Intention}

One of the key goals of e-commerce business models is the optimization of technology-enabled purchases and maximization of customer retention by employing customer relationship management (Hamid \& McGrath 2005). To get a better understanding of how to achieve these goals, IS researchers have studied the antecedents of online purchasing and customer retention variables, e.g., satisfaction and loyalty (Chen 2012a; Kumar et al. 2013; Suh \& Yi 2012). In the context of e-commerce, customer satisfaction and loyalty are of major importance for online purchase intention or purchasing behaviour (Massad et al. 2006; McKinney et al. 2002; Shankara et al. 2003). As such, customer satisfaction leads to loyalty to the company and results in repeated purchases (Anderson \& Srinivasan 2003; Zeithaml 2000). Further research on satisfaction with services in e-commerce settings demonstrates a significant influence of satisfaction on intention to use an online service (Zhang et al. 2006). Particularly in the online 
space, customers have high expectations and, hence, push e-commerce companies in their efforts to achieve customer satisfaction (Bhattacherjee 2001a).

The number of transaction phases supported through a channel (e.g., online) translates into how a company seeks to achieve customer satisfaction. Different phase support means different opportunities to offer a service or product to a customer. If all phases in an ecommerce business model are supported a customer can carry out the entire transaction within one channel and the transaction can be completed without the need to switch to another channel. In this case, the customer can finalize the transaction quickly and without any delays (Berry et al. 2002). The full-phase transaction support represents a component in an ecommerce business model that requires only low levels of user engagement.

However, some e-commerce business models offer customers additional services and enhanced customer care through partial transaction support in one channel. These additional offerings can be provided because customers are directed and hence, requested to switch from the online or mobile channel to the direct customer-company communication channel. The rationale for the company may be that the online channel is not appropriately equipped to offer a particular service or because the company seeks to enhance customer intimacy, as suggested in the business models of travel service providers such as Flightcentre.com or Flightfox.com. In such cases, opportunities for additional sales or improved customer services are presented. From the customer's viewpoint, partial transaction support results from companies' wish to have direct interaction with the customer and thus increase their customer engagement (Attfield et al. 2011). Moreover, Tate et al. (2005) point out that close customer relationships in e-commerce settings can increase retention rates and, thus, raise profitability for the company. At the same time, the forced channel switching means that the customer cannot complete the transaction and must wait until the company contacts him or her. This implementation of the website is despite technological abilities to support all transaction phases. For example, additional support that goes beyond a website's channel capability - as in the case of Flightcentre.com and Flightfox.com - is only accessible if the customer leaves the online channel (Bang et al. 2013). In any case, the forced channel switch causes a delay of the transaction completion. As IS research has shown, delays in online transactions can be perceived as a flaw that may ultimately have a negative impact on continuation to use the website (Everard \& McCoy 2010). In a similar vein, any features that irritate customers during the interaction with a website (e.g., interruptions) deteriorate the customer experience and hence, have a negative impact on attitude and usage intention (Lim 2014). To summarize, partial transaction support will result in positive customer experiences due to higher customer engagement and interaction, but may also be less appreciated by customers due to delays of transaction completion.

The literature argues that customers value convenience in their online shopping endeavours and high levels of convenience have resulted in increased degrees of customer satisfaction and usage intention (Zhang et al. 2006). Perceived convenience includes transaction convenience, which captures the fact that low mental effort and little time is required of the customer to complete a transaction (Berry et al. 2002). The ability to complete a transaction online without any interruptions is, therefore, likely to increase convenience. Hence, we expect that a website that supports all transaction phases will evoke a more favourable reaction from users than a website that requires switching to another channel. In a similar vein, we suggest that a website that provides value in the form of convenience has a higher chance of continued use, i.e., that it is reused (Adapa \& Cooksey 2013). Previous research from a different angle, i.e., the ecommerce success model (Wang 2008) has shown that satisfaction impacts reuse intention of an e-commerce website (Wang et al. 2016). Conversely, we argue that customers do not value any extra services they may receive through direct customer-company communication enough to outweigh the lack of convenience of partial transaction support. More specifically, we posit that a website that fully supports all transaction phases will achieve higher satisfaction and a higher intention to reuse the website, than a website that provides only partial transaction support. 
Hypothesis 1: Satisfaction with a website is more likely if all transaction phases are supported.

Hypothesis 2: Intention to reuse a website is more likely if all transaction phases are supported.

\subsection{Impact of Experience on Customer Satisfaction and Usage Intention}

User satisfaction with a website and the user's decision to reuse the website is tightly connected with their prior experiences. The literature shows that prior experiences influence user skills and, therefore, users' expectations of an IS (DeLone 1988; Fuerst \& Cheney 1982; Hong et al. 2002; Lee 1986). In the context of Internet experience, Kuhlmeier \& Knight (2005) demonstrate that Internet skills positively impact online purchases. Channel expansion theory (Carlson \& Zmud 1999) aids in explaining the relationship between users' experiences and online purchases. This theory considers user experience an important antecedent for the user's perception of an information and communication technology (ICT) (e.g., mobile channel, online channel). Among other claims, the theory asserts that users' prior experiences with the technology and the communication context increase the perceived value of the ICT and, in turn, users' satisfaction with the channel (Ogara et al. 2014).

The literature distinguishes between two different types of prior experience because, in a technology-enabled environment, the experience construct is multilayered. First, experience with the product or service itself, also referred to as cross-domain experience with the service (Bhatnagar et al. 2003), and second, experience with the online transaction that relates to the service, also known as within-domain experience (Bhatnagar et al. 2003). User experience of both types creates knowledge that allows users to apply leaner channels for more demanding tasks (Carlson \& Zmud 1999). As Brunelle (2009) demonstrates in a quantitative study, a customer's experience with the online channel and their experience with product purchase both positively influence their intention to use an online store for information gathering as well as for online purchasing (Brunelle 2009; Carlson \& Zmud 1999).

In this study, we distinguish between experience resulting from the frequency of service consumption in general (usage frequency of a service) and experience resulting from the frequency of purchasing this service online (online purchasing frequency of a service). As prior research shows, experiences with a service from a different channel (cross-domain) and experiences with a service purchased in the same channel (within-domain) equally influence the formation of online expectations (Bhatnagar et al. 2003). Frequent users of the general service and the online execution of the service will, therefore, have higher expectations. According to the expectation-confirmation theory, higher expectations lead to lower confirmation that, in turn, leads to lower satisfaction (Bhattacherjee 2001b). Thus, we propose:

Hypothesis 3: Users with high service experience are less likely to be satisfied with a website that only partially supports transaction phases online.

Hypothesis 4: Users with high service experience are less likely to reuse a website that only partially supports transaction phases online.

Hypothesis 5: Users with high experience with online service purchasing are less likely to be satisfied with a website that only partially supports transaction phases online.

Hypothesis 6: Users with high experience with online service purchasing are less likely to reuse a website that only partially supports transaction phases online.

Finally, we propose that users who are experienced in both experience types - that is, the service itself and online service purchasing - display a lower satisfaction and intention to reuse if the website only supports a single transaction phase. This argument is again in line with the expectation-confirmation theory, which postulates that higher expectations lead to lower confirmation that, in turn, leads to lower satisfaction (Bhattacherjee 2001b). 
Hypothesis 7: Users with high experience with both the service and online service purchasing are less likely to be satisfied with a website that only partially supports transaction phases online.

Hypothesis 8: Users with high experience with both the service and online service purchasing are less likely to reuse a website that only partially supports transaction phases online.

\section{Research Methodology}

The empirical testing of the above hypotheses was performed using an experimental research design. Experiments are a preferred methodology when the researchers seek to control for extraneous factors that would otherwise confound the results (Cook \& Campbell 1979). Indeed, experiments allow for increased internal validity and specifically tailor the empirical investigation to a particular problem (Zikmund 2003). As we elaborate in more detail below, our empirical research design involves exposure to two websites, one offering a service with support of all transaction phases and the other offering support of the information phase only.

The experimental design was set up as a laboratory experiment to maximize precision (Dennis \& Valacich 2001). The experiment was designed as a one-shot case study (Malhotra et al. 2012) with two treatments (i.e., the two websites) followed by measurement with a questionnaire. We followed guidelines for experimental research in determining several requirements for setting up the websites to be used as stimuli in the experiment (Kirk 2013; Shadish et al. 2002). First, to ensure participants concentrated on the transactions rather than various other aspects of usage of the website, the websites had to have low complexity. In doing so, we minimized participants' cognitive load and a possibly confounding impact of participants' varying levels of navigation and interaction skills and thus, ease of use. Further the website design aimed at avoiding distraction from carrying out the transaction (Agarwal \& Karahanna 2000). Second, the websites needed to be based on otherwise identical e-commerce business models that only differed in the transaction phase support. We have purposefully not included any customercompany interactions that take place once the direct link between the customer and the company has been established, as it is the case in the partial transaction phase support. Third, any other exogenous influences on satisfaction and reuse (for example promotions, special packages or visual elements) needed to be eliminated, thus requiring that the websites were identical in all respects other than the support of transaction phases. These conditions led to the conclusion that real commercial websites were not eligible for the experiment. In an attempt to ensure that all the above-mentioned conditions were met, the websites were developed specifically for the experimental design.

\subsection{Subjects}

Subjects in this experiment were 54 undergraduate and graduate business students at an Austrian university. Researchers need to ascertain that their sample size is adequate to avoid that an effect is found in the data that may not reflect a true effect (Hair et al. 2009). To ensure the size of the sample is adequate, we determined the statistical power using the software $\mathrm{G}^{*}$ Power 3 (Faul et al. 2007). Assuming an alpha of 0.05, a statistical power of 0.8 and an effect size of 0.4 resulted in a minimum required sample size of 32 , which is less than the sample size in the study. Hence, we concluded a sufficient large sample size for explaining moderate population effects, however, the sample would not be sufficient for explaining strong population effects using covariance-based path modelling.

A student population is considered appropriate for this research as this group is influential and a representative gatekeeper for spreading opinion and information regarding Internet content (Su 2007). University students are suitable subjects on whom to conduct an experiment that focuses on Internet purchasing transactions given that Internet buyers tend to be young, well educated and have high levels of computer literacy (Swinyard \& Smith 2003).

The average age in the sample was 25 years and $29.4 \%$ were female. The gender bias was a result of a high proportion of male students in the university programme. However, male Internet users still comprise the majority of online shoppers according to various statistics. In 
2015, 62.6\% of men shopped online within the preceding 12 months, whereas only $52.9 \%$ of women did (Statistik Austria 2016). Similarly, certain age groups dominate among online shoppers. Together comprising more than $80 \%$ of online shoppers, the age groups of 16 to 24 years and 25 to 35 years still dominate among Internet consumers (Statistik Austria 2016). Based on these statistics, we conclude that the sample sufficiently represents Internet shoppers.

Subjects were invited to participate in the study during a regular class and the experiment was conducted immediately after that class. The experiment took place in a computer lab with PCs of identical configuration. The subjects were randomly assigned to commence the experiment on one of the two websites. Once each group finished their booking with their starting website, they swapped and performed the second experimental task, i.e., booking via the other website.

\subsection{Materials}

The materials used were the two websites and an accompanying questionnaire. Both were pretested with a separate group of five students. As a result, the websites were optimized in terms of wording. The two websites were developed using HTML and simulated simplified travel agency websites with identical visual design and navigation, offering the necessary functionalities to book domestic and international flights, which was also confirmed in our pretest. In the laboratory experiment both websites only included features that were necessary for carrying out the transaction in order to avoid distraction from carrying out the booking tasks. The websites were assigned invented names: "Dream Flight" and "Flight Heaven".

The study welcome page introduced the study, explained the experimental task, provided links to both travel websites and obtained consent from the students. The structure of the two websites was as follows. Dream Flight allowed the user to conduct all transaction phases online. It comprised five single web pages: the welcome page of the travel agency, a page with domestic flight offers (time, price, airline), a page with international flight offers (time, price, airline), a page with booking and payment details, and a final confirmation page with the reference number. No additional services or assistance were available during the transaction. The second website, Flight Heaven, supported the information phase only. It also comprised five single web pages: the welcome page and pages with domestic and international flight offers were duplicated from Dream Flight, while the remaining two pages unique to Flight Heaven covered the following. On one page, the benefits of the website only supporting the information phase were presented. Customers were told that they could receive a number of value-adding services through personal contact with the service operators, such as advice about accommodation options, offerings of discounted hotels, tailored tours, travel insurance or particular flight times to the chosen destination. Furthermore, this page requested customer contact details for future contact through Flight Haven and a final web page with information on the response time for the flight requests. Hence, this website provided the promise of a soon callback service as an additional service offering, but terminated the online transaction after the information phase.

\subsection{Procedure}

Each subject conducted the entire experiment without interruption. An instructor provided the subjects with the URL and a password to access the study. The subjects were instructed to use the assigned website to book two flights, viz. a domestic flight and an international, longdistance flight within a specified date range and to look for the cheapest flights. In the first phase of the experiment, one portion of the subjects conducted the experiment with the website Dream Flight, while the remaining subjects used the website Flight Heaven. After completion of these online tasks, the subjects were asked to fill out a questionnaire. In the second phase of the experiment, the two groups performed the same tasks with the other website. Again, the subjects were asked to conduct the experimental tasks of booking the two flights, before completing a survey questionnaire. 


\subsection{Measurements}

The measurement items utilized were adapted from the literature. The questionnaire measured satisfaction, reuse intention, frequency of flight booking (experience with the service), proportion of online booking (experience with online purchasing of the service) and socio-demographic data.

The items used to measure customer satisfaction and reuse intention were taken from the web customer satisfaction scale by McKinney et al. (2002) using a 7-point Likert scale. We slightly modified the items of both constructs to adapt them to the experimental task and the tourism context, in particular the air travel industry (Granados et al. 2007). Table 1 and Table 2 show the results of the reliability analyses including consistency, convergent validity and discriminant validity. Cronbach's alpha and composite reliability values are higher than the recommended value of 0.7 and thus deemed acceptable (Hair et al. 2009; Nunnally 1978). Convergent validity is satisfactory if the average variance extracted (AVE) is higher than 0.5 (Fornell \& Larcker 1981). With 0.775 and 0.946 respectively, this condition is met for both multi-item constructs. Further, the loadings of the individual items on the corresponding variables are well above the recommended value of 0.5 for appropriate discriminant validity.

\begin{tabular}{|l|l|l|l|l|l|l|l|l|l|}
\hline \multicolumn{1}{|c|}{ Variable } & \multicolumn{1}{|c|}{ Items } & Min & Max & Mean & SD & Loadings & $\begin{array}{c}\text { Cronbach's } \\
\text { alpha }\end{array}$ & $\begin{array}{c}\text { Composite } \\
\text { reliability }\end{array}$ & AVE \\
\hline Satisfaction & SATI1 & 1 & 7 & 3.81 & 1.560 & $0.867^{* * *}$ & 0.903 & 0.932 & 0.775 \\
(SATI) & SATI2 & 1 & 7 & 3.84 & 1.243 & $0.908^{* * *}$ & & & \\
& SATI3 & 1 & 7 & 3.99 & 1.225 & $0.907^{* * *}$ & & & \\
& SATI4 & 1 & 7 & 4.19 & 1.147 & $0.838^{* * *}$ & & & \\
\hline Reuse \\
$\begin{array}{l}\text { intention } \\
\text { REUSE) }\end{array}$ & REUSE1 & 1 & 7 & 3.63 & 1.698 & $0.974^{* * *}$ & 0.943 & 0.972 & 0.946 \\
\hline$* * * \mathrm{p}<0.001$ & REUS2 & 1 & 7 & 3.34 & 1.642 & $0.971^{* * *}$ & & & \\
\hline
\end{tabular}

Table 1: Reliability measures of the variables.

The frequency of general service consumption (flight booking) was measured as a single item (Chuanlan \& Forsythe 2010) with a 4-point scale (less than once a year, once to twice a year, three to five times a year, and more than five times a year). The online flight booking experience was also measured as a single item by asking for the proportion of flights booked online (Chang \& Samuel 2004) using four answer categories (never, less than half of the flights, more than half of the flights, and for each flight).

Table 2 presents the numbers concerning discriminant validity. The numbers in italics are the square roots of the AVE. For adequate discriminant validity, these values should exceed the inter-construct correlations. This condition is met for all constructs. Given the strong results of the consistency, convergent validity and discriminant validity, the results of the measurement model are considered acceptable.

\begin{tabular}{|l|l|l|l|l|l|l|}
\hline \multicolumn{1}{|c|}{ Variable } & Mean & \multicolumn{1}{|c|}{ SD } & Satisfaction & $\begin{array}{c}\text { Reuse } \\
\text { intention }\end{array}$ & $\begin{array}{c}\text { Product or service } \\
\text { experience }\end{array}$ & $\begin{array}{c}\text { Online } \\
\text { channel } \\
\text { experience }\end{array}$ \\
\hline Satisfaction & 3.96 & 1.139 & 0.880 & & & \\
\hline Reuse intention & 3.49 & 1.625 & $0.832^{* *}$ & 0.973 & & \\
\hline $\begin{array}{l}\text { Product or service } \\
\text { experience }\end{array}$ & 2.38 & 0.930 & -0.042 & -0.055 & N/A & N/A \\
\hline $\begin{array}{l}\text { Online channel } \\
\text { experience }\end{array}$ & 2.09 & 1.077 & $0.208^{*}$ & 0.158 & 0.025 & \\
\hline$*$ p 0.05 (2-tailed), ** $\mathrm{p}<0.01(2$-tailed) & & & \\
\hline
\end{tabular}

Table 2: Descriptive statistics and discriminant validity. 


\section{Results}

\subsection{The Bayesian Network}

Data analysis was performed by means of a Bayesian network, which is an appropriate approach for building models in a context with intrinsic uncertainty (Lauría \& Duchessi 2007). Whereas commonly used statistical tests (e.g., structural models) seek to generalize findings and provide statistical significance, their use is questionable in cases of small data samples. Indeed, Zheng \& Pavlou (2010) elaborate on the use of Bayesian networks to overcome limitations of structural equation modelling. Bayesian networks permit supporting measurement models, but they also help to identify the most likely causal structure in a structural model. Consequently, the Bayesian network approach has been applied in various IS studies to gain enhanced insights into novel research fields, e.g., concerning success factors in IT projects (Gingnell et al. 2014) and IS security factors (Feng et al. 2014).

Bayesian networks are well established in computer science and operations research as they enable researchers to make predictions using conditional probabilities (Korb \& Nicholson 2004). Our choice was motivated by the benefits of Bayesian networks. They are sensitive to the smallest changes in the data and, hence, detect variances on the dependent variable. Further, they are independent of the sample size. Finally, Bayesian networks are particularly powerful in representing uncertain knowledge (Ghosh \& Valtorta 2000) and permit the analysis of "what-if" questions (Lauría \& Duchessi 2007). In general, Bayesian networks can be used either for diagnostic reasoning or predictive reasoning (Korb \& Nicholson 2004). We use them here for the latter.

Bayesian networks are also termed belief networks, causal probabilistic networks or probabilistic influence diagrams (Xenos 2004). A Bayesian network contains two elements: nodes (displayed as tables) and directed arcs (displayed as arrows). The nodes represent the mathematical variables of the constructs (satisfaction, reuse intention, experiences). The arcs are the relationships between the nodes (Jensen 1997). The output of a Bayesian network allows for a consistent estimation of the way in which the input probabilities impact uncertain conclusions - for example, on the Internet users' future reuse intentions.

To utilize the Bayesian network, we had to conduct certain preparatory analyses. First, we needed to test whether the order in which the subjects had used the two websites had influenced their answers. A randomly assigned portion of the subjects tested Dream Flight first and Flight Heaven second, while the other group worked the other way around. An ANOVA showed no significant differences between these two groups. Therefore, we excluded a bias due to the order of the website interactions. Second, a Bayesian network requires entering probabilities for each investigated node. Thus, we determined the probabilities of the variables, i.e., experience with flight booking, experience with online flight booking, satisfaction and intention to reuse. For this purpose, we reduced complexity and performed a scale transformation on the data by transforming the original 7-point and 4-point scales into simplified 3-point and 2-point scales.

For satisfaction and reuse intention, answers ranging from one to three were summarized as "negative" answers, answers ranging from five to seven were treated as "positive" answers, and answers that were exactly four were assigned as "neutral" answers. Similarly, we transformed the experience items into two categories respectively by assigning the first two answer categories to "low" experience and the last two categories to "high" experience. Following this scale transformation, the frequencies of each variable's different states in the sample were computed. All frequencies of combinations between the variables were recorded in truth tables and then entered as probabilities into the Bayesian network. Therefore, the Bayesian network presents only data that represent the structure of probabilities within the experimental sample. The Bayesian network was configured using the open source software BayesBuilder. This tool was developed by Stichting Neural Networks (SNN) at the University of Nijmegen, Netherlands (SNN-Adaptive-Intelligence 2013). 


\subsection{Initial Model of the Bayesian Network}

The calculation of the Bayesian network using the transformed data created the following probability structures for both experimental websites, that is, Dream Flight with full transaction support and Flight Heaven with support of the information phase only.

To analyse the data with a Bayesian network the creation of an initial model is required. Its structure is depicted in Figure 2 and is interpreted as follows: to measure the impact of experience on satisfaction and reuse intention, we considered flight booking experiences (left node) and online booking experiences (right node). In the first step, we computed the probabilities based on the data, providing the results in Figure 2.

Dream Flight

(full support of transaction)

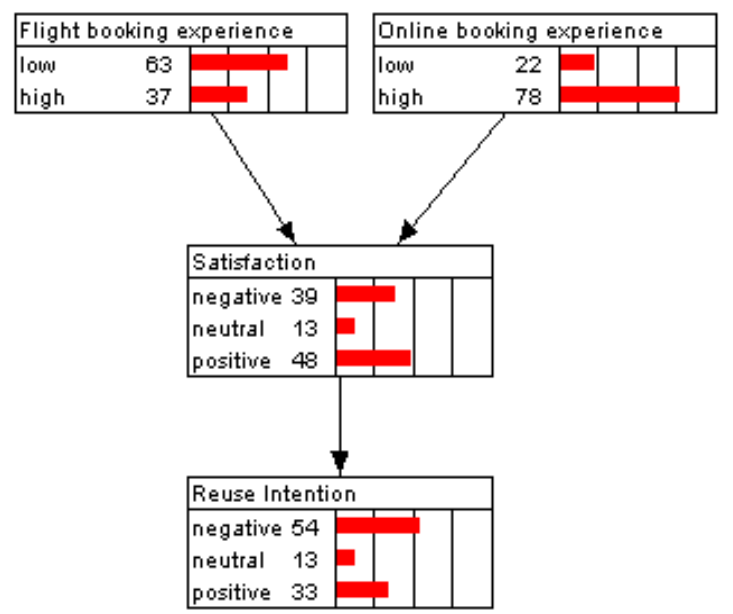

Flight Heaven

(support of information phase only)

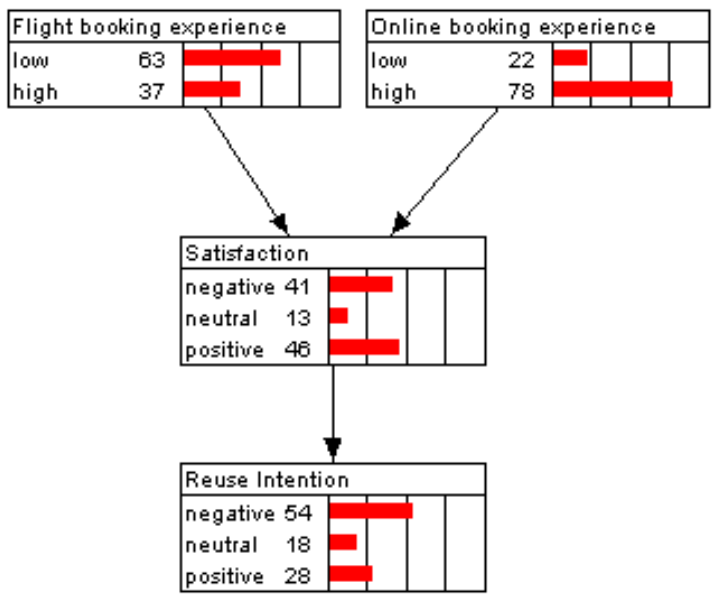

Figure 2. Bayesian network of both websites.

Figure 2 can be interpreted as follows: in the flight booking experience node, the majority of participants have low experience with flight booking since $63 \%$ answered they had little or no experience and $37 \%$ answered that they had high or very high booking experience. Therefore, the probability in the sample that one subject is experienced in flight booking is $37 \%$. In contrast, the online booking experience node shows that most of the participants (78\%) book the majority of their flights online and thus are experienced with online flight booking. Both websites show similar probabilities of satisfaction - that is $48 \%$ for Dream Flight and $46 \%$ for Flight Heaven. The difference between these two probabilities is small, thus we do not accept hypothesis 1. Concerning intention to reuse, the probability of reuse intention is $33 \%$ for Dream Flight and 28\% for Flight Heaven. Therefore, the website that supports the information phase only is less likely to be reused than the website that supports the entire transaction, as postulated in hypothesis 2. At this point, it is important to notice that the acceptance or rejection of each proposition is not derived from statistical significance tests but from differences in probabilities in the research sample.

To test the further propositions with the Bayesian networks, the probabilities were punched, that is, the conditional probabilities of satisfaction and reuse intention were calculated by determining the levels of experience in advance. In other words, it was defined that one particular subject shows a certain level of experience before computing the corresponding probabilities of satisfaction and reuse intention. In terms of the Bayesian network, this means that we refer to an observed case (Ypma et al. 2004), that is, a subject who is experienced in booking flights or purchasing flights online. 


\subsection{High Flight Booking Experience in the Bayesian Network}

First, we calculated the probabilities of various satisfaction levels and reuse intention for users who have high experience with flight booking. In Figure 3, the punches are the blue bars and the red bars refer to the conditional probabilities that occur among these experienced users. Thus, Figure 3 presents the impact of user experience regarding general service consumption on satisfaction and reuse intention for both websites.

Dream Flight

(full support of transaction)

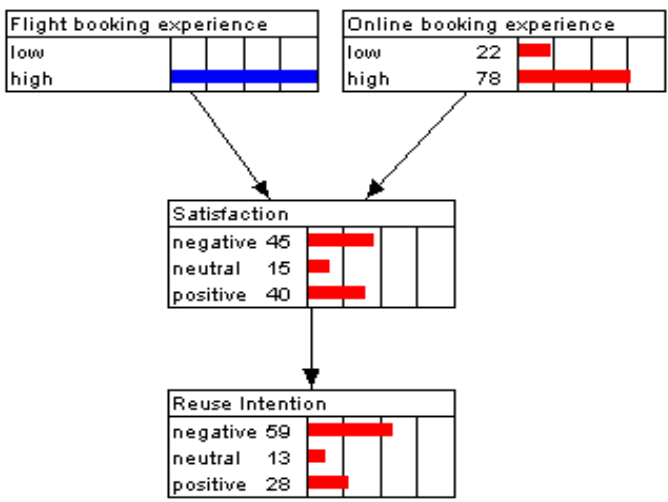

Flight Heaven

(support of information phase only)

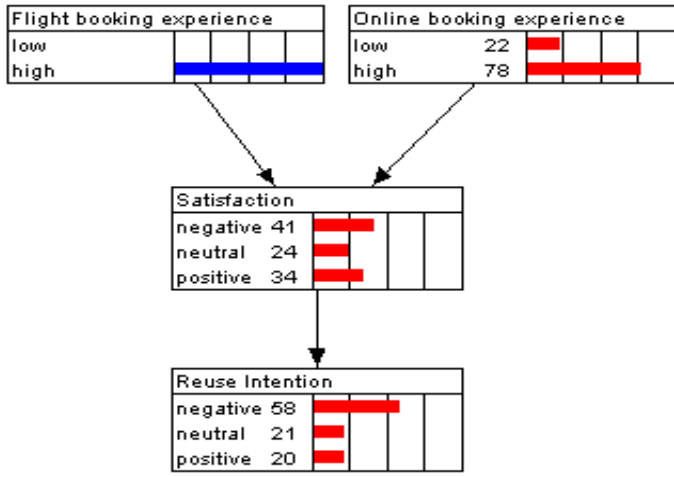

Figure 3. Probability structure with predefined high experience with flight booking

The probability of high satisfaction is considerably larger for Dream Flight (40\%) than for Flight Heaven (34\%). Hypothesis 3 is therefore supported, which presumes that users experienced with flight booking are less likely to be satisfied with the website that supports only the information phase. When it comes to intention to reuse, we observe that the probability is again larger for Dream Flight, which offers the entire transaction online (28\% for Dream Flight vs. 20\% for Flight Heaven). Therefore, hypothesis 4 can also be supported.

\subsection{High Online Booking Experience in the Bayesian Network}

Figure 4 presents the probabilities in case of high experience with online flight booking for both websites. For this purpose, we punched the experience with online booking, i.e., we defined that one particular subject shows a high level of online booking experience. We then computed the corresponding probabilities of satisfaction and reuse intention.

Dream Flight

(full support of transaction)

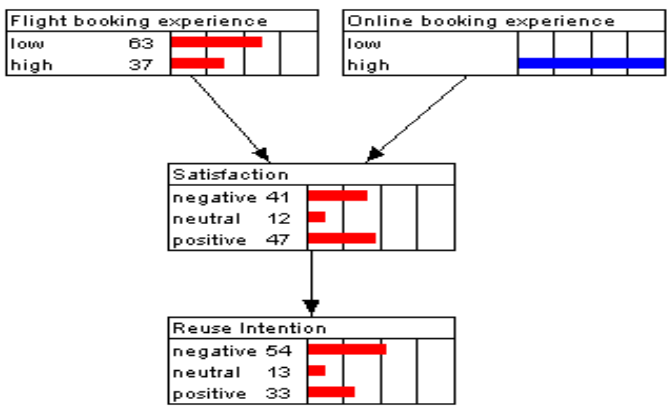

Flight Heaven

(support of information phase only)

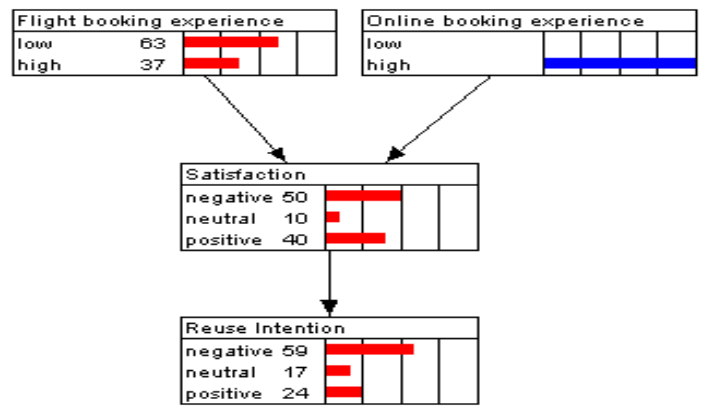

Figure 4. Probability structure with predefined high experience with online flight booking 
In the context of users who book most of their flights online, we observe that users are again more likely to be satisfied with Dream Flight (47\%) than with Flight Heaven (40\%). It can further be noticed that Dream Flight has a considerably lower likelihood of dissatisfied users (41\%) than Flight Heaven (50\%). This finding conforms to hypothesis 5. Reuse intention is also higher for Dream Flight (33\% probability) than for Flight Heaven (24\%). Hence, Flight Heaven achieves worse results than Dream Flight in this regard, which supports hypothesis 6.

\subsection{High Flight Booking Experience and High Online Booking Experience in the Bayesian Network}

Finally, we investigated the effect when users have high levels of both types of experience simultaneously. For this purpose, we punched high experiences with both flight booking in general and online flight booking. Figure 5 shows the results.

Dream Flight

(full support of transaction)

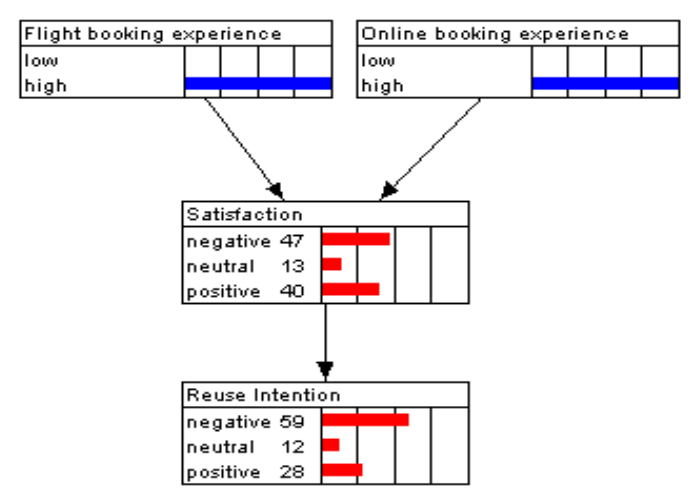

Flight Heaven

(support of information phase only)

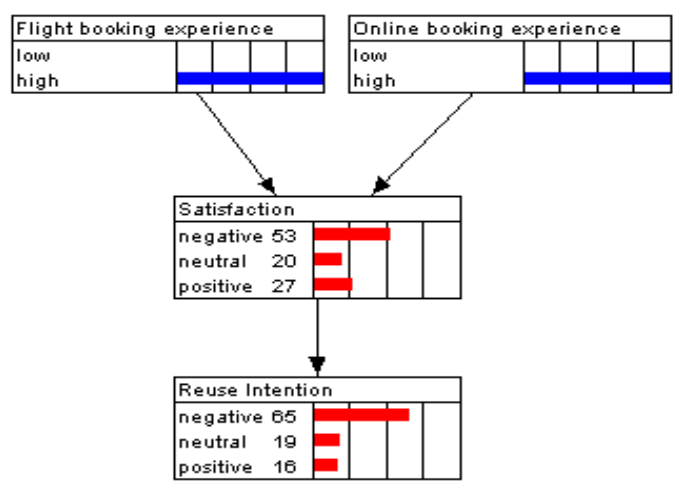

Figure 5. Probability structure with predefined high experience with flight booking and online flight booking

As the above results indicate, the largest differences between the two websites are found here. Amongst users who are highly experienced in both dimensions, Dream Flight achieves considerably better results than Flight Heaven. The probability that experienced users are satisfied with Dream Flight is $40 \%$ while it is $27 \%$ for Flight Heaven. With regard to dissatisfaction, users return a likelihood of $47 \%$ for Dream Flight and $53 \%$ for Flight Heaven. The differences are also considerable concerning reuse intention. Given that the users are experienced both with booking flights and booking flights online, the likelihood that Dream Flight is reused is $28 \%$ while it is only $16 \%$ for Flight Heaven. With regard to user reports of not intending to reuse the website, the likelihood for Dream Flight is $59 \%$ versus $65 \%$ for Flight Heaven. Thus, among experienced users, Dream Flight achieves considerably better results than Flight Heaven, which supports hypotheses 7 and 8.

\subsection{Summary of Results}

Summarizing the findings, the results show that customers are equally likely to be satisfied with the fully- and partly-supported booking transactions. However, reuse intention is more likely for the fully-supported transaction. Despite the promise of potential additional service offerings, we can observe that, for all combinations of experience (experience with the booking process generally, experience with online booking, and both), the full support of all transaction phases enjoys higher probabilities for positive customer reactions than does the support of only the information phase. Table 3 summarizes our results. 


\begin{tabular}{|l|c|}
\hline \multicolumn{1}{|c|}{ Hypothesis } & $\begin{array}{c}\text { Supported/ } \\
\text { Rejected }\end{array}$ \\
\hline $\begin{array}{l}\text { H1: Satisfaction with a website is more likely if all transaction phases are } \\
\text { supported. }\end{array}$ & Rejected \\
\hline $\begin{array}{l}\text { H2: Intention to reuse a website is more likely if all transaction phases are } \\
\text { supported. }\end{array}$ & Supported \\
\hline $\begin{array}{l}\text { H3: Users with high service experience are less likely to be satisfied with a website } \\
\text { that only partially supports transaction phases online. }\end{array}$ & Supported \\
\hline $\begin{array}{l}\text { H4: Users with high service experience are less likely to reuse a website that only } \\
\text { partially supports transaction phases online. }\end{array}$ & Supported \\
\hline $\begin{array}{l}\text { H5: Users with high experience with online service purchasing are less likely to be } \\
\text { satisfied with a website that only partially supports transaction phases online. }\end{array}$ & Supported \\
\hline $\begin{array}{l}\text { H6: Users with high experience with online service purchasing are less likely to } \\
\text { reuse a website that only partially supports transaction phases online. }\end{array}$ & Supported \\
\hline $\begin{array}{l}\text { H7: Users with high experience with both the service and online service } \\
\text { purchasing are less likely to be satisfied with a website that only partially supports } \\
\text { transaction phases online. }\end{array}$ & Supported \\
\hline $\begin{array}{l}\text { H8: Users with high experience with both the service and online service } \\
\text { purchasing are less likely to reuse a website that only partially supports } \\
\text { transaction phases online. }\end{array}$ & Supported \\
\hline
\end{tabular}

Table 3. Summary of results

\section{Discussion}

Our research aimed to identify the impact of online transaction phase support on user satisfaction and reuse intention in e-commerce business models. In particular, we examined the impact of partially-supported transaction phases on customers' perception of the two variables. In addition, we sought to characterize the type of user that prefers different levels of online support of transaction phases. We found evidence in a first exploratory study that experienced users - that is, users who are familiar with the general service consumption and/or online purchase of the service - are less satisfied and have a lower intention to reuse the website if it forces them to switch to another channel of communication or distribution. Experienced users evaluate the website that supports only the information phase less favourably as compared to a website offering complete transaction support.

\subsection{Contributions to Theory}

Our research contributes in various ways to the existing literature in IS and marketing, especially in the areas of e-commerce business models, e-commerce, channel design and channel switching, and to prior research on customer satisfaction and reuse. We elaborate on these four main contributions in detail as follows.

First, we contribute to the literature on e-commerce business models by introducing the concept of transaction phases into a business model. Prior research has produced core definitions for these phenomena and created a number of frameworks, typologies and research agendas to classify, evaluate and innovate e-commerce business models (Veit et al. 2014). These studies have laid a solid foundation for further research to delve more deeply into specific aspects of the e-commerce business model and perform empirical research but have not integrated the view of transaction phases into e-commerce business models. Our study highlights the e-commerce business model's concept of transaction phases and varying transaction support in one channel as a strategic factor for companies to create value and coordinate their business resources (Osterwalder et al. 2005). Testing the extent to which full transaction support impacts satisfaction and reuse intention as compared to partial support provides initial empirical evidence for this concept of a business model. The results clearly show that benefits of e-commerce business models that provide partial support of transaction phases in the form of increased customer engagement cannot offset the negative impacts of the inherent delay in transaction completion through channel switching. Thus, the study endorses 
findings of e-commerce literature on general drivers of customer satisfaction and reuse intention at the level of single transaction phases (Wang 2008; Chen 2012; Liao et al. 2011).

Extending our understanding of e-commerce business models in this regards is important considering the increasing variety of electronic devices that can be used for online purchasing. Ubiquitous mobile devices facilitate shopping online independent of location (Bang et al. 2013) and, as such, offer opportunities to complete the entire purchasing transaction in the mobile channel alone without the need to switch to another channel, while benefiting from location information in the form of more tailored service offerings.

Our second contribution is to the e-commerce literature, demonstrating the impact of transaction phase support and varying degrees of user experience while conducting online shopping. Prior research has theorized about transaction phases in e-commerce, their impact on website adoption and the advantages of e-commerce over traditional purchasing processes (Choudhury \& Karahanna 2008; Pavlou \& Fygenson 2006). Our findings show that transaction phases also influence a user's perception of a website regarding satisfaction and reuse intention. By investigating the role of prior experiences, we accounted for an antecedent of satisfaction and reuse intention that has been investigated in different IS contexts (Roca et al. 2006; Wang 2003) but less frequently in e-commerce research (Chen 2012). The construct of prior experiences concerning customers' familiarity with online purchasing and the service/product booking offered both have an impact on how users evaluate the website.

The third contribution relates to the marketing literature on channel design and channel switching. Prior research has indicated the importance of multi-channel design and the opportunities possible for customers when switching between channels (Brynjolfsson et al. 2013; Hansen \& Sia 2015; Pookulangara et al. 2011; Verhoef et al. 2015). However, this body of research did not discuss switching in regards to the phases of the transaction and when best to implement the switch. It is implicitly assumed that customers value switching between different channels during the purchasing process. Our research findings illustrate that when customers are forced to switch channels they experience lower degrees of satisfaction and are less likely to reuse the website. As such, our research suggests that, when multiple channels are offered, each channel should provide the possibility of completing the transaction.

Fourth, we contribute to the literature on customer satisfaction and reuse. Our findings demonstrate that satisfaction and reuse intention - two core concepts of customer loyalty creation - are affected by the support of transaction phases. Extensive research on satisfaction and reuse in e-commerce settings has shown that these two variables are impacted by service quality (Kettinger et al. 2009; Setia et al. 2007), perceived value (Wang 2008), perceived usefulness and system quality (Setia et al. 2007), and regret (Liao et al. 2011). With our study, we propose transaction phase support as a new antecedent of satisfaction and reuse intention of websites. Understanding which phases need to be supported within a channel to achieve high customer satisfaction and reuse intention is important as it determines the degree to which a customer is ultimately loyal to the business.

\subsection{Implications for Practice}

This research provides a number of implications for practice. First, from a managerial perspective, we suggest considering transaction phases an essential aspect of the e-commerce business model for a company to define on a fine-grained basis. By explicitly referring to the support of transaction phases, companies are encouraged to realize a more strategy-oriented plan of their e-commerce websites. In fact, support of transaction phases may be regarded as a means of differentiation. We do not entirely call for a maximization of transaction phases supported online, but rather point to the necessity of identifying the optimal number and kind of supported online transaction phases. If a firm decides to support only single transaction phases online, this must be part of a well-considered e-commerce strategy. In particular, firms should consider the nature of the offered products or services as well as key contextual factors. For example, in case of products or services that are usually purchased after an extensive purchase decision (d'Astous et al. 1989), customers may feel more satisfied if they are directed to a service-oriented channel with personal interactions and additional assistance. On the 
other hand, in case of limited or habitual purchase decisions or if products of low complexity are involved, customers might prefer to complete the transaction in the original selected channel. In any case e-commerce firms should not settle for only partial online support of transaction phases due to limitations of their online or mobile presence.

Second, we raise the issue of target groups of e-commerce customers. If companies cater to highly experienced users - a situation that applies, for example, to industries with standardized products, a relatively "long" e-commerce history and digital natives - these users have an expectation that they will be able to complete a transaction quickly, without delays or disruptions. However, companies can potentially offer extra value-adding services through direct customer-company interactions once users switch from the online/mobile channel to the direct customer-company communication channel. It seems that customers do not appreciate these services to the same extent as they value full transaction phase support. Hence, companies must be aware of customers' experience levels and the low ratings of satisfaction and reuse intention partial transaction phase support triggers. Indeed, companies should consider that a lack of transaction phase support may have negative impacts on their image and the other channels they offer.

Furthermore, the decision of transaction phase support in an e-commerce business model becomes even more prevalent in environments of technological constraints where forced channel switching is not a customer engagement strategy but the only possibility to sell products and services. Compared with industrialized countries, the growth rate of the Internet is significantly higher in developing countries despite some economic and technological constraints such as affordable Internet access (Worldbank 2016). Consequently, the relevance of e-commerce business models is rising due to increasing Internet penetration in developing countries assuming improvements in economic conditions and technological infrastructure (McCoy et al. 2012). Hence, companies that expand to regions with rapidly growing Internet penetration may be faced with technological constraints that require their e-commerce business models to enforce channel switching.

\subsection{Limitations and Future Research}

Like any research, this study has several limitations that should be considered when examining the results. First, we have compared just two channels: the online and the offline channel. It may be that this selection of channels influenced users' satisfaction and reuse intention. Second, we have tested the differences in transaction support in the service sector, more specifically the tourism industry. Therefore, it is possible that the results are valid for this scenario alone and not transferable to other sectors, such as the retail sector. Third, the present study is a very simplistic model of user-specific antecedents of satisfaction and reuse intention, which only incorporates prior experiences.

Therefore, this research suggests a number of future research directions. First, although our channel design involved only two channels, a variety of different channels exist - including mobile and social media channels - that entail a multitude of channel switching opportunities. Thus, we suggest including different channels when testing for partial transaction support. It could potentially be the case, for example, that the disadvantages and advantages of the mobile channel, such as small screen size and a lack of appropriate mobile apps, in concert with the benefits of transmitting location data, result in different findings regarding satisfaction and reuse intention.

Second, we only differentiated between three transaction phases. While the trisection (i.e., information, agreement and fulfilment) is the division that is most often used in the literature, we suggest examining forced channel switching with more than three transaction phases. In such an investigation, the channel switching could be forced at multiple points of the transaction and potentially result in different findings, as users might appreciate the receipt of after-sales services in a different and more personal channel.

Third, we have examined prior experience as an impact factor for how satisfied a customer is with the website and whether he/she intends to reuse it. There are a number of other factors 
that may also have such an impact (Monsuwé et al. 2004). These factors include personal characteristics of the customer (e.g., self-efficacy, online trust), characteristics of the purchasing process (e.g., task/product/service complexity, task/product/service familiarity) and characteristics of the company (e.g., domain knowledge of the provider). Examining the impact these factors can have on user experience enlarges our collective knowledge base regarding e-commerce business models and provides a better understanding of appropriate transaction phase support in various channels.

Another future research topic may compare the satisfaction and reuse of the combined channel experience including the forced switching. In this way, an entire purchasing process is compared and potentially changing dynamics of satisfaction and re-use intention may emerge. Finally, we set up the experiment as a laboratory experiment to achieve a high internal validity. Future research should complement these insights with a field experiment involving existing websites that apply forced channel switching in their business models.

\section{Conclusion}

In this research, we investigate the impact of varying degrees of trasaction phase support on customer satisfaction and reuse intention in e-commerce settings. Our theoretical foundation is based on the literature of e-commerce business models, transaction phases and channel expansion theory. We test a model by providing users with two online websites: one with full transaction support and the other with only partial transaction support. For each condition and based on the users' levels of experience, we determined their degree of satisfaction and reuse intention. Our exploratory study shows that varying online support of transaction phases influences reuse intention depending on the experience a user possesses. In case of high experience with the service in general, and particularly the online purchasing of the service, reuse intention and satisfaction decrease if not all transaction phases are supported. These findings contribute to a more nuanced conceptualization of e-commerce business models considering transaction phases and user experience, and an improved understanding of channel design and users' perceptions of forced channel switching.

\section{References}

Adapa, S., \& Cooksey, R. (2013) "Factors Affecting Consumers' Continued Use of Internet Banking: Empirical Evidence from Australia", Australasian Journal of Information Systems, 18(1): 5-31.

Agarwal, R., \& Karahanna, E. (2000) "Time Flies When You're Having Fun: Cognitive Absorption and Beliefs About Information Technology Usage", MIS Quarterly, 24(4): 665-694.

Al-Debei, M.M., \& Avison, D. (2010) "Developing a Unified Framework of the Business Model Concept", European Journal of Information Systems, 19(3): 359-376.

Alba, J., Lynch, J., Weitz, B., Janiszewski, C., Lutz, R., Sawyer, A., \& Wood, S. (1997) "Interactive Home Shopping: Consumer, Retailer, and Manufacturer Incentives to Participate in Electronic Marketplaces", Journal of Marketing, 61(3): 38-53.

Amblee, N., \& Bui, T. (2011) "Harnessing the Influence of Social Proof in Online Shopping: The Effect of Electronic Word of Mouth on Sales of Digital Microproducts", International Journal of Electronic Commerce, 16(2): 91-114.

Amit, R., \& Zott, C. (2001) "Value Creation in E-Business", Strategic Management Journal, 22(6/7): 493-520.

Anagnostopoulos, I., Anagnostopoulos, C., Loumos, V., \& Kayafas, E. (2004) "Classifying Web Pages Employing a Probabilistic Neural Network", IEEE Proceedings Software, 151(3): 139-150.

Anderson, R.E., \& Srinivasan, S.S. (2003) "E-Satisfaction and E-Loyalty: A Contingency Framework", Psychology and Marketing, 20(2): 123-138. 
Attfield, S., Kazai, G., Lalmas, M., \& Piwowarski, B. (2011) "Towards a Science of User Engagement (Position Paper)", WSDM'11 Conference, Hong Kong.

Bang, Y., Lee, D.-J., Han, K., Hwang, M., \& Ahn, J.-H. (2013) "Channel Capabilities, Product Characteristics, and the Impacts of Mobile Channel Introduction", Journal of Management Information Systems, 30(2): 101-126.

Berry, L.L., Seiders, K., \& Grewal, D. (2002) "Understanding Service Convenience", Journal of Marketing, 66(3): 1-17.

Bhatnagar, N., Lurie, N., \& Zeithaml, V. (2003) "Reasoning About Online and Offline Service Experiences: The Role of Domain-Specificity in the Formation of Service Expectations", Advances in Consumer Research, 30(1): 383-384.

Bhattacherjee, A. (2001a) "An Empirical Analysis of the Antecedents of Electronic Commerce Services Continuance", Decision Support Systems, 32(2): 201-214.

Bhattacherjee, A. (2001b) "Understanding Information Systems Continuance: An Expectation-Confirmation Model", MIS Quarterly, 25(3): 351-370.

Brunelle, E. (2009) "Introducing Media Richness into an Integrated Model of Consumers' Intentions to Use Online Stores in Their Purchase Process", Journal of Internet Commerce, 8(3/4): 222-245.

Bunn, M.D. (1993) "Taxonomy of Buying Decision Approaches", Journal of Marketing, 57(1): 38-56.

Cao, L. (2014) "Business Model Transformation in Moving to a Cross-Channel Retail Strategy: A Case Study", International Journal of Electronic Commerce, 18(4): 69-96.

Carlson, J.R., \& Zmud, R.W. (1999) "Channel Expansion Theory and the Experiental Nature of Media Richness Perceptions", Academy of Management Journal, 42(2): 153-170.

Chang, J., \& Samuel, N. (2004) "Internet Shopper Demographics and Buying Behaviour in Australia", Journal of American Academy of Business, Cambridge, 5(1/2): 171-176.

Chen, Y.-Y. (2012) "Why Do Consumers Go Internet Shopping Again? Understanding the Antecedents of Repurchase Intention", Journal of Organizational Computing \& Electronic Commerce, 22(1): 38-63.

Chesbrough, H., \& Rosenbloom, R.S. (2002) "The Role of the Business Model in Capturing Value from Innovation: Evidence from Xerox Corporation's Technology Spin-Off Companies", Industrial and Corporate Change, 11(3): 529-555.

Choudhury, V., \& Karahanna, E. (2008) "The Relative Advantage of Electronic Channels: A Multi-Dimensional View", MIS Quarterly, 32(1): 179-200.

Chuanlan, L., \& Forsythe, S. (2010) "Post-Adoption Online Shopping Continuance", International Journal of Retail \& Distribution Management, 38(2): 97-114.

Cook, T.D., \& Campbell, D.T. (1979) Quasi-Experimentation: Design and Analysis Issue, Houghton Mifflin, Boston, MA.

d'Astous, A., Bensouda, I., \& Guindon, J. (1989) "A Re-Examination of Consumer Decision Making for a Repeat Purchase Product: Variations in Product Importance and Purchase Frequency", Advances in Consumer Research, 16(1): 433-438.

Daidj, N. (2015) Developing Strategic Business Models and Competitive Advantage in the Digital Sector, IGI Global, Hershey, PA.

Dennis, A.R., \& Valacich, J.S. (2001) "Conducting Research in Information Systems", Communications of the Association for Information Systems, 7(5): 1-41.

eMarketer (2015) Worldwide Retail Ecommerce Sales: Emarketer's Updated Estimates and Forecast

through

2019.

Available

at: 
http://www.emarketer.com/public_media/docs/eMarketer_eTailWest2016_Worldwid e_ECommerce_Report.pdf [Accessed 8 March 2016].

Everard, A., \& McCoy, S. (2010) "Effect of Presentation Flaw Attribution on Website Quality, Trust, and Abandonment", Australasian Journal of Information Systems, 16(2): 5-19.

Faul, F., Erdfelder, E., Lang, A.-G., \& Buchner, A. (2007) "G*Power 3: A Flexible Statistical Power Analysis Program for the Social, Behavioral, and Biomedical Sciences", Behavior Research Methods, 39(2): 175-191.

Feng, N., Wang, H.J., \& Li, M. (2014) "A Security Risk Analysis Model for Information Systems: Causal Relationships of Risk Factors and Vulnerability Propagation Analysis", Information Sciences, 256(1): 57-73.

Fornell, C., \& Larcker, D.F. (1981) "Evaluating Structural Equation Models with Unobservable Variables and Measurement Error", Journal of Marketing Research, 18(1): 39-50.

Ghosh, J.K., \& Valtorta, M. (2000) "Building a Bayesian Network Model of Heart Disease", 38th Annual Southeast Regional Conference Clemson, ACM Press, South Carolina, 239240.

Gingnell, L., Franke, U., Lagerström, R., Ericsson, E., \& Lilliesköld, J. (2014) "Quantifying Success Factors for IT Projects - an Expert-Based Bayesian Model", Information Systems Management, 31(1): 21-36.

Granados, N.F., Gupta, A., \& Kauffman, R.F. (2007) "IT-Enabled Transparent Electronic Markets: The Case of the Air Travel Industry", Information Systems and E-Business Management, 5(1): 65-91.

Gupta, A., Su, B., \& Walter, Z. (2004) "An Empirical Study of Consumer Switching from Traditional to Electronic Channels: A Purchase-Decision Process Perspective", International Journal of Electronic Commerce, 8(3): 131-161.

Hair, J.F., Black, W.C., Babin, B.J., \& Anderson, R.E. (2009) Multivariate Data Analysis, Pearson, Harlow.

Hamid, N.R.A., \& McGrath, M.G. (2005) "The Diffusion of Internet Interactivity on Retail Web Sites: A Customer Relationship Model", Communications of the IIMA, 5(2): 35-46.

Hammer, M., \& Champy, J. (2003) Reengineering the Corporation: A Manifesto for Business Revolution, Harper Collins, New York, NY.

Herhausen, D., Binder, J., Schoegel, M., \& Herrmann, A. (2015) "Integrating Bricks with Clicks: Retailer-Level and Channel-Level Outcomes of Online-Offline Channel Integration", Journal of Retailing, 91(2): 309-325.

Huang, L., Lu, X., \& Ba, S. (2016) "An Empirical Study of the Cross-Channel Effects between Web and Mobile Shopping Channels", Information and Management, 53(2): 265-278.

Jensen, F. (1997) An Introduction to Bayesian Networks, Springer, New York.

Kettinger, W.J., Park, S.-H., \& Smith, J. (2009) "Understanding the Consequences of Information Systems Service Quality on IS Service Reuse", Information and Management, 46(6): 335-341.

Kim, J., \& Lee, J. (2002) "Critical Design Factors for Successful E-Commerce Systems", Behaviour and Information Technology, 21(3): 185-199.

Kirk, R.E. (2013) Experimental Design. Procedures for the Behavioral Sciences, Sage Publications, Thousand Oaks.

Kollmann, T., Kuckertz, A., \& Kayser, I. (2012) "Cannibalization or Synergy? Consumers' Channel Selection in Online-Offline Multichannel Systems", Journal of Retailing and Consumer Services, 19(2): 186-194. 
Korb, K.B., \& Nicholson, A.E. (2004) Bayesian Artificial Intelligence, Chapman \& Hall/CRC, London, UK.

Kotler, P.T., \& Keller, K.L. (2015) Marketing Management, Pearson Education, Prentice Hall.

Kuhlmeier, D., \& Knight, G. (2005) "Antecedents to Internet-Based Purchasing: A Multinational Study", International Marketing Review, 22(4): 460-473.

Lauría, E.J.M., \& Duchessi, P.J. (2007) "A Methodology for Developing Bayesian Networks: An Application to Information Technology (IT) Implementation", European Journal of Operational Research, 179(1): 234-252.

Lehmann, J., Lalmas, M., Yom-Tov, E., \& Dupret, G. (2012) "Models of User Engagement", UMAP'12 20th International Conference on User Modeling, Adaptation, and Personalization, Springer, 164-175.

Liang, T.-P., \& Turban, E. (2011) "Introduction to the Special Issue Social Commerce: A Research Framework for Social Commerce", International Journal of Electronic Commerce, 16(2): 5-14.

Liao, C., Liu, C.-C., Liu, Y.-P., To, P.-L., \& Lin, H.-N. (2011) "Applying the Expectancy Disconfirmation and Regret Theories to Online Consumer Behavior", CyberPsychology, Behavior and Social Networking, 14(4): 241-246.

Lim, W.M. (2014) "Antecedents and Consequences of E-Shopping: An Integrated Model", Internet Research, 25(2): 184-217.

Lindner, M. (2016) Younger Consumers Turn Increasingly to Mobile Devices for Buying as Well as Browsing. Available at: https://www.internetretailer.com/2016/04/25/younger-consumers-turn-increasinglymobile-devices-buying [Accessed 25 May 2016].

Malhotra, N.K., Birks, D.F., \& Wills, P. (2012) Marketing Research. An Applied Approach, Pearson Education, Essex.

Matook, S., Brown, S.A., \& Rolf, J. (2015) "Forming an Intention to Act on Recommendations Given Via Online Social Networks", European Journal of Information Systems, 24(1): 76-92.

McCoy, S., Cha, H.S., \& Durcikova, A. (2012) "Modeling Internet Diffusion in Developing Countries", Australasian Journal of Information Systems, 17(2): 5-23.

McKinney, V., Yoon, K., \& Zahedi, F.M. (2002) "The Measurement of Web-Customer Satisfaction: An Expectation and Disconfirmation Approach", Information Systems Research, 13(3): 296-315.

Monsuwé, T.P., Dellaert, B.G.C., \& de Ruyter, K. (2004) "What Drives Consumers to Shop Online? A Literature Review", International Journal of Service Industry Management, 15(1): 102-121.

Morris, M., Schindehutte, M., \& Allen, J. (2005) "The Entrepreneur's Business Model: Toward a Unified Perspective", Journal of Business Research, 58(6): 726-735.

Nunnally, J.C. (1978) Psychometric Theory, McGraw-Hill, New York, NY.

Ogara, S.O., Koh, C.E., \& Prybutok, V.R. (2014) "Investigating Factors Affecting Social Presence and User Satisfaction with Mobile Instant Messaging", Computers in Human Behavior, 36(2): 453-459.

Osterwalder, A., Pigneur, Y., \& Tucci, C. (2005) "Clarifying Business Models: Origins, Present, and Future of the Concept", Communications of the Association for Information Systems, 15(1): 1-25. 
Parker, C.M., Bellucci, E., Torlina, L., Fraunholz, B., \& Zutshi, A. (2014) "Conceptualising How SMEs Incorporate Green Content in Their Websites", Australasian Journal of Information Systems, 18(3): 137-160.

Pateli, A., \& Giaglis, G. (2004) "A Research Framework for Analysing Ebusiness Models", European Journal of Information Systems, 13(4): 302-314.

Pavlou, P.A., \& Chai, L. (2002) "What Drives Electronic Commerce across Cultures? A CrossCultural Empirical Investigation of the Theory of Planned Behavior", Journal of Electronic Commerce Research, 3(4): 240-253.

Pavlou, P.A., \& Fygenson, M. (2006) "Understanding and Predicting Electronic Commerce Adoption: An Extension of the Theory of Planned Behavior", MIS Quarterly, 30(1): 115143 .

Piotrowicz, W., \& Cuthbertson, R. (2014) "Introduction to the Special Issue Information Technology in Retail: Toward Omnichannel Retailing", International Journal of Electronic Commerce, 18(4): 5-16.

Pookulangara, S., Hawley, J., \& Xiao, G. (2011) "Explaining Consumers' Channel-Switching Behavior Using the Theory of Planned Behavior", Journal of Retailing and Consumer Services, 18(4): 311-321.

Prasarnphanich, P., \& Gillenson, M.L. (2003) "The Hybrid Clicks and Bricks Business Model", Communications of the ACM, 46(12): 178-185.

Roca, J.C., Chiu, C.-M., \& Martínez, F.J. (2006) "Understanding E-Learning Continuance Intention: An Extension of the Technology Acceptance Model", International Journal of Human-Computer Studies, 64(8): 683-696.

Rohm, A.J., \& Swaminathan, V. (2004) "A Typology of Online Shoppers Based on Shopping Motivations", Journal of Business Research, 57(7): 748-757.

Schmid, B., \& Lindemann, M. (1998) "Elements of a Reference Model for Electronic Markets", 31st Hawaii International Conference on System Sciences (HICSS-35), Hawaii, HI, 193201.

Setia, P., Boyer, K.K., Calantone, R.J., \& Voorhees, C.M. (2007) "Complementary Effects of Value and Satisfaction on Customer's Behavioral Intentions", Academy of Management Annual Meeting, 1-6.

Shadish, W.R., Cook, T.D., \& Campbell, D.T. (2002) Experimental and Quasi-Experimental Designs for Generalized Causal Inference, Hougthon-Mifflin, Boston, MA.

Slade, P., \& Van Akkeren, J. (2002) "Business on-Line? An Empirical Study of Factors Leading to the Adoption of Internet Technologies by Australian SMEs", Australasian Journal of Information Systems, 10(1): 50-64.

SNN-Adaptive-Intelligence (2013) Bayesbuilder: A Tool for Constructing and Testing Bayesian Networks. Available at: www.snn.ru.nl

Statista (2016) Retail E-Commerce Sales Worldwide from 2014 to 2019. Available at: http://www.statista.com/statistics/379046/worldwide-retail-e-commerce-sales/ [Accessed 30 June 2016].

Statistik Austria (2016) Online-Shopper 2015. Available at: www.statistik.at/wcm/idc/idcplg?IdcService=GET_PDF_FILE\&RevisionSelectionMet hod $=$ LatestReleased\&dDocName $=022211$ [Accessed 25 April 2016].

Steinfield, C., Bouwman, H., \& Adelaar, T. (2002) "The Dynamics of Click-and-Mortar Eletronic Commerce: Opportunities and Management Strategies", International Journal of Electronic Commerce, 7(1): 93-119. 
Su, B.-C. (2007) "Consumer E-Tailer Choice Strategies at on-Line Shopping Comparison Sites", International Journal of Electronic Commerce, 11(3): 135-159.

Swinyard, W., \& Smith, S. (2003) " Why People (Don't) Shop Online: A Lifestyle Study of the Internet Consumer", Psychology and Marketing, 20(7): 567-597.

Tate, M., Hope, B., \& Coker, B. (2005) "The Buywell Way: Seven Essential Practices of a Highly Successful Multi-Channel E-Tailer", Australasian Journal of Information Systems, 12(2): 147-163.

Teece, D.J. (2010) "Business Models, Business Strategy and Innovation", Long Range Planning: International Journal of Strategic Management, 43(2-3): 172-194.

van Doorn, J., Lemon, K.N., Mittal, V., Nass, S., Pick, D., Pirner, P., \& Verhoef, P.C. (2010) "Customer Engagement Behavior: Theoretical Foundations and Research Directions", Journal of Service Research, 13(3): 253-266.

Veit, D., Clemons, E., Benlian, A., Buxmann, P., Hess, T., Kundisch, D., Leimeister, J.M., Loos, P., \& Spann, M. (2014) "Business Models - an Information Systems Research Agenda", Business and Information Systems Engineering - Research Notes, 6(1): 45-53.

Wallace, D.W., Giese, J.L., \& Johnson, J.L. (2004) "Customer Retailer Loyalty in the Context of Multiple Channel Strategies", Journal of Retailing, 8o(4): 249-263.

Wang, W.-T., Wang, Y.-S., \& Liu, E.-R. (2016) "The Stickiness Intention of Group-Buying Websites: The Integration of the Commitment-Trust Theory and E-Commerce Success Model", Information and Management, 53): 625-642.

Wang, Y.-S. (2003) "Determinants of User Acceptance of Internet Banking: An Empirical Study", International Journal of Service Industry Management, 14(5): 501-519.

Wang, Y.S. (2008) "Assessing E-Commerce Systems Success: A Respecification and Validation of the DeLone and McLean Model of IS Success ", Information Systems Journal, 18(5): 529-557.

Wiesel, T., Pauwels, K., \& Arts, J. (2011) "Practice Prize Paper-Marketing's Profit Impact: Quantifying Online and Offline Funnel Progression", Marketing Science, 30(4): 604611.

Worldbank (2016) Internet Users (Per 100 People). Available at: http://data.worldbank.org/indicator/IT.NET.USER.P2?end=2015\&start=2010 [Accessed 2016/11/29].

Xenos, M. (2004) "Prediction and Assessment of Student Behaviour in Open and Distance Education in Computers Using Bayesian Networks", Computers and Education, 43(4): 345-359.

Ypma, A., Westerdijk, M., de Walle, H.-J., \& Heskes, T. (2004) "Bayesian Techniques for Modelling Dynamic Patterns", 4th European Symposium on Intelligent Technologies, Hybrid Systems and their Implementation on Smart Adaptive Systems, Aachen, Germany.

Zeithaml, V.A. (2000) "Service Quality, Profitability, and the Economic Worth of Customers: What We Know and What We Need to Learn", Journal of the Academy of Marketing Science, 28(1): 67-85.

Zhang, X., Prybutok, V., \& Huang, A. (2006) "An Empirical Study of Factors Affecting EService Satisfaction", Human Systems Management, 25(4): 279-291.

Zheng, Z., \& Pavlou, P.A. (2010) "Toward a Causal Interpretation from Observational Data: A New Bayesian Networks Method for Structural Models with Latent Variables", Information Systems Research, 21(2): 365-391.

Zikmund, W.G. (2003) Business Research Methods, Thomson/South-Western, Mason, OH. 
Zott, C., \& Amit, R. (2007) "Business Model Design and the Performance of Entrepreneurial Firms", Organization Science, 18(2): 181-199.

Zott, C., \& Amit, R. (2010) "Designing Your Future Business Model: An Activity System Perspective", Long Range Planning, 43(2010): 216-226.

Zott, C., Amit, R., \& Massa, L. (2011) "The Business Model: Recent Developments and Future Research", Journal of Management Information Systems, 37(4): 1019-1042.

Zumpe, S., \& Madlberger, M. (2007a) "Serving Online Customers Better in the Tourism Industry", Information Age, 2007(11/12): 48-52.

Zumpe, S., \& Madlberger, M. (2007b) "A Transaction-Based Framework for Business Models in Electronic Commerce", 11th Pacific Asia Conference on Information Systems (PACIS 2007), Auckland, New Zealand, 106-121.

Copyright: (C) 2017 Madlberger \& Matook. This is an open-access article distributed under the terms of the Creative Commons Attribution-NonCommercial 3.0 Australia License, which permits non-commercial use, distribution, and reproduction in any medium, provided the original author and AJIS are credited.

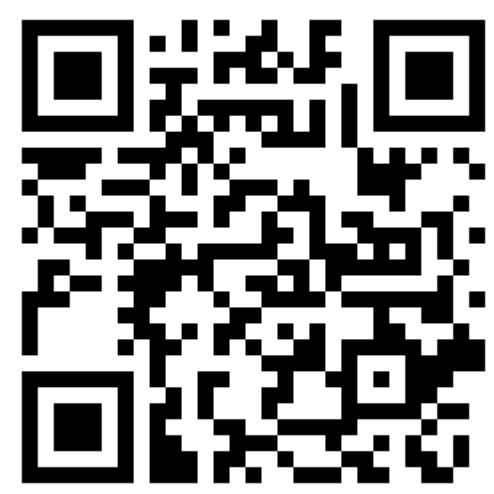

